\title{
Penetration Testing Untuk Deteksi Vulnerability Sistem Informasi Kampus
}

\author{
Sahren', Ruri Ashari Dalimuthe' ${ }^{2}$ Muhammad Amin ${ }^{3}$ \\ STMIK Royal Kisaran \\ sahren.one@gmail.com ${ }^{1}$, ruriashari1986@gmail.com²,stmikroyal13@gmail.com³
}

\begin{abstract}
Security is an effort that can be done to protect the information contained in it which refers to confidentiality. Information systems that are centrally prone to various types of attacks such as DoS, SQL Injections, Cross Site Scripting (XSS), Clickjacking, CSRF / Crosssite request forgery and so on. This will be a polemic for the information service owner and manager. The method to be carried out in this study is to do penetration testing to audit the security of the campus information system webserver. This activity aims to identify and exploit vulnerabilities in the web server. In this study, several tools will be used as a tool, including WHOIS, NMAP and Acunetix Web Vulnerability Scanner. Tests carried out are to look for vulnerabilities on the web server while the level of vulnerability that will be detected in this test sawill be inter alia higt risk, Medium risk and low risk. The aim is to find out the weaknesses in the web server so that in the future it can avoid DoS attacks, CSRF / Cross-site request forgery, Cross Site Scripting (XSS) and clickjacking. The results of this test are expected to be an input for the management of campus information systems for the future can be made improvements to existing weaknesses.
\end{abstract}

Keywords: Penetration Testing, Vulnerability, CSRF, Clickjacking, Acunetix

Abstrak-Keamanan merupakan upaya yang dapat dilakukan guna melindungi informasi yang terdapat didalamnya yang mana mengacu kepada kerahasiaan. Sistem informasi yang secara terpusat sangat rawan terhadap berbagai macam serangan seperti DoS, SQL Injectiion, Cross Site Scripting (XSS), Clickjacking, CSRF/ Cross-site request forgery dan lain sebagainya. Hal ini akan menjadi sebauh polemik bagi pemilik dan pengelola layanan sebuah informasi. Metode yang akan dilakukan pada penelitian ini adalah dengan melakukan penetration testing untuk mengaudit keamanan webserver sistem informasi kampus. Kegiatan ini bertujuan untuk mengidentifikasi dan eksploitasi kerentanan pada webserver. Pada penelitian ini akan digunakan beberapa tools sebagai alat bantu antara lain WHOIS, NMAP dan Acunetix Web Vulnerabilty Scanner. Pengujian yang dilakukan adalah untuk mencari vulnerability pada web server adapun tingkatan vulnerability yang akan dideteksi dalam pengujian ini nantinya antar lain higt risk, Medium risk dan low risk. Tujuannya adalah untuk mengetahui kelemahan pada webserver supaya kedepannya dapat menghindari dari serangan DoS, CSRF/ Cross-site request forgery, Cross Site Scripting (XSS) maupun clickjacking. Hasil dari pengujian ini diharapkan dapat sebagai bahan masukan kepada pihak pengelola sistem informasi kampus untuk kedepannya dapat dilakukan perbaikan terhadap kelemahan yang ada.

Kata kunci: Penetration Testing, Vulnerability, CSRF, Clickjacking, Acunetix

\section{PENDAHULUAN}

Sistem informasi yang secara terpusat sangat rawan terhadap berbagai macam serangan seperti DoS, SQL Injectiion, Cross Site Scripting (XSS), Clickjacking, CSRF/ Cross-site request forgery dan lain sebagainya. Seorang penyerang akan 
menyerang sistem kemanan jaringan dengan tujuan untuk mengalahkan layanan keamanan pada fasilitas jaringan tersebut. Dengan mempertimbangkan fakta bahwa jaringan public pada awalnya dirancang untuk keterbukaan tanpa mempertimbangkan keamanan, jelas membuka peluang akan terjadi kejahatan [2]. Hacker dengan kemampuan tinggi dapat melakukan remote setelah mendapat celah dengan melakukan serangan SQL Injection. Dimana hacker dapat mengirimkan script dengan mengunakan script khusus ke website tertentu dengan cara melakukan teknik rekayasa sistem. Serangan Cross Site Scripting (XSS) adalah jenis injeksi dengan mengirimkan kode-kode script berbahaya. Umumnya dalam bentuk script ke sisi browser pada pengguna akhir yang berbeda [8]. Selain bentuk serangan tersebut terdapat bentuk serangan lainnya yang cukup populer pada masa sekarang ini yaitu clikjacking. Clickjacking adalah sebuah ancaman yang muncul di web. Serangan ini merupakan salah satu contoh trik pengambilan data, dengan modus penipuan, serangan ini berpotensi mengirimkan perintah yang tidak sah atau mengungkapkan informasi rahasia sementara korban berinteraksi pada halaman web yang tampaknya tidak berbahaya [5]. Celah ini muncul biasanya dikarenakan X-Frame Header Option yang tidak di set pada web server. Untuk dapat mengurangi kerugian yang diakibatkan oleh para hacker, maka langkah awal yang harus dikembangkan adalah melakukan evaluasi terhadap keamanan server yang ada. Hal ini bertujuan untuk mengurangi resiko terjadinya penyalahgunaan terhadap sumber daya yang ada pada suatu perguruan tinggi atau pun kampus. Sebagian besar orang di suatu instansi akan merasa bingung dan kesulitan saat diminta untuk melakukan evaluasi atau audit keamanan server yang ada. Hal ini dikarenakan memang banyak orang yang merasa awam untuk melakukan evaluasi server. Istilah Penetration testing atau yang lebih dikenal dengan penetrasi adalah serangkaian kegiatan yang dilakukan untuk mengidentifikasi dan mengeksploitasi kerentanan yang ada [7]. Oleh karena adanya permasalahan tersebut maka kebutuhan yang penting saat ini adalah membantu meminimalisir dan mengantisipasi server yang ada dari kejahatan hacking.

Beberapa penelitian terdahulu telah banyak dilakukan berkaitan dengan penetration testing. [7] melakukan penelitian untuk menganalisa perbandingan Penetration Testing Tool untuk menguji suatu aplikasi web. [1] melakukan penelitian untuk menganalisa kelemahan port pada pengguna public WiFi. [3] melakukan penelitian untuk menganalisa keamanan suatu website dengan metode scanning serta menerapkan peritungan security matriks dan menggunakan formula base score untuk mengukur tingkat kerentanan jaringan apakah low medium atau high. Tujuan pada penelitian ini adalah menggunakan metode penetration testing untuk mencari kelemahan (vulnerability) yang ada pada sistem informasi kampus untuk kemudian akan dijadikan sebagai bahan evaluasi oleh pihak terkait.

\section{METODOLOGI PENELITIAN}

Metodologi penelitian ini dilakukan secara sistematik yang bisa digunakan sebagai pedoman atau acuan untuk peneliti ketika melaksanakan penelitian agar hasil yang dicapai tidak menyimpang dan tujuan yang diinginkan bisa terlaksana dengan baik, benar dan sesuai terhadap apa yang telah ditentukan sebelumnya.

\subsection{Kerangka Kerja Penelitian (Frame Work)}


Kerangka kerja penelitian merupakan langkah-langkah yang harus dilakukan dalam penelitian hingga mencapai suatu kesimpulan. Adapun alur penelitian yang penulis gunakan terlihat pada gambar berikut ini:

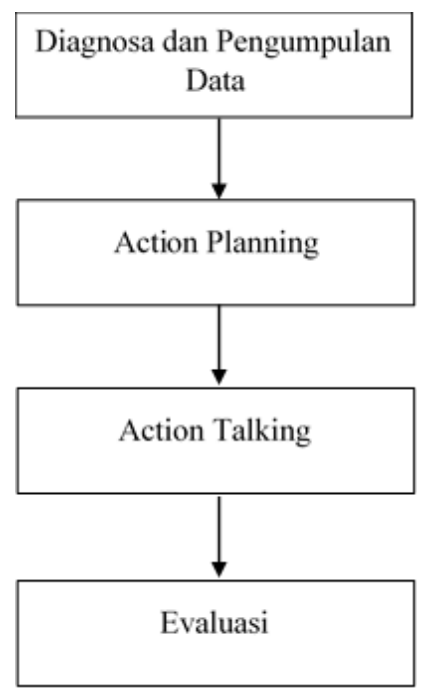

Gambar 1. Kerangka Penelitian

Berdasarkan kerangka kerja pada gambar 1 maka dapat diuraikan langkah kerja sebagai berikut :

1. Diagnosa dan Pengumpulan Data

Pengumpulan data merupakan hal yang sangat penting dalam sebuah penelitian. Dalam penelitian ini pengumpulan data penulis lakukan melalui :

a. Jurnal-jurnal yang penulis jadikan sebagai referensi adalah jurnal yang berkaitan dengan sistem pembuatan informasi online dalam pembuatan laporan yang berhubungan dengan judul yang penulis tulis.

b. Buku yang berrhubungan dengan penelitian yang dilakukan. Buku yang penulis gunakan sebagai referensi adalah buku yang berkaitan dengan judul penulis tulis.

\section{Action Planing}

Tahap kedua adalah membuat rencana tindakan (Action Planning) tahapan ini peneliti melakukan pemahaman pokok masalah yang ada dan menyusun rencana tindakan yang tepat untuk menyelesaikan masalah yang ada. Peneliti akan mulai menyusun rencana pengujian yang akan dilakukan pada sistem informasi.

\section{Action Talking}

Tahap ketiga adalah melakukan tindakan (Action Taking) mengimplementasikan rencana tindakan yang telah disusun. Pada langkah ini peneliti mulai melakukan tahapan-tahapan investigasi guna mendapatkan informasi kelemahan.

4. Evaluasi

Tahap keempat adalah melakukan evaluasi (Evaluating) setelah tahapan Action Taking dilaksanakan peneliti mulai melakukan evaluasi pada hasil dari implementasi sebelumnya dan mulai menyimpulkan hasil dari langkah sebelumnya. Hasil dari evaluasi ini adalah berupa daftar celah kemanan dari 
sistem informasi yang telah diketemukan pada proses sebelumnya, hasil temuan ini akan memberikan sebuah kesimpulan mengenai tingkat keamanan dari web server itu sendiri.

\subsection{Pengertian Keamanan jaringan}

Keamanan jaringan adalah sebuah upaya untuk melakukan kendali terhadap akses sumberdaya jaringan, akses jaringan dikontrol supaya hanya bisa diakses oleh siapa saja yang berhak dan menghalangi dari yang tidak berhak [6]. Menurut Garfinkel, yang merupakan pakar dalam bidang security. Kemanan komputer terdiri dari empat aspek yaitu, privacy, integrity, authentication dan availability.

a. Privacy atau confidentiality.

Privacy atau kerahasiaan informasi. Inti dari aspek ini adalah bagaimana menjaga kerahasiaan dari informasi agar tidak dapat dilihat atau diakses oleh orang yang tidak memiliki hak sama sekali [6].

b. Integrity

Aspek integrity atau biasa juga disebut sebagai integritas mencakup keutuhan atau orisinalitas informasi [6]. maksud dari aspek ini adalah bagaimana infomasi agar tetap utuh. Sebuah informasi tidak boleh diubah, baik ditambah maupun dikurangi informasi tersebut kecuali atas izin dari pihak yang memiliki kewenangan.

\section{c. Authentication}

Aspek authentication, mensyaratkan ketika pengiriman suatu informasi bisa untuk diidentifikasi dengan baik dan benar serta memberikan jaminan bahwa indentitas yang diperoleh adalah benar atau tidak palsu.

d. Availability

Aspek yang ke 4 ini berkaitan dengan ketersediaan informasi. Sesuatu yang dibutuhkan oleh pengguna layanan teknologi informasi haruslah dapat dipenuhi sehingga tingkat ketersediaan informasi dapat.

Berkaitan dengan aspek security di atas, seorang pakar security yang bernama W. Stallings. Juga mengemukakan pendapatnya yakni ada beberapa kemungkinan serangan yang terjadi terhadap keamanan suatu sistem informasi, yaitu interuption, interception, modification dan fabrication. Tiga serangan yaitu interuption, modification dan fabrication ini digolongkan kedalam serangn aktif. Sedangkan interception bisa kita golongkan kedalam bentuk serangan pasif. Dalam jenis serangan ini penyerang akan mengirim suatu aliran data ke salah satu atau kedua kelompok yang terlibat komunikasi dan akan menotong aliran data [4].

\subsection{Penetration Testing}

Berdasarkan definisi dalam modul CEH, Penetration Testing merupakan metode evaluasi keamanan sistem komputer atau jaringan dengan mensimulasikan serangan dari sumber yang berbahaya dan merupakan bagian dari security audit. Simulasi serangan yang dilakukan dibuat seperti kasus yang bisa dibuat oleh black hat hacker, cracker, dan sebagainya. Tujuannya adalah menentukan dan mengetahui macam - macam serangan yang mungkin dilakukan pada sistem beserta akibat yang bisa terjadi karena kelemahan sistem. 
Dalam melakukan penetration testing, diperlukan analisa intensif untuk setiap kerentanan yang diakibatkan oleh kelemahan sistem. Nantinya setelah seluruh analisa selesai dilakukan, akan didokumentasikan dan diberikan kepada pemilik beserta solusi dan dampak yang dapat diakibatkan dari celah keamanan yang ada.

Hal - hal yang perlu diuji dalam penetration testing ada banyak, hal ini dibutuhkan untuk mengidentifikasi ancaman - ancaman utama seperti kegagalan komunikasi, e-commerce, dan kehilangan informasi rahasia. Selain itu ketika berhadapan dengan infrastruktur publik, seperti situs, gateway e-mail, akses jarak jauh, DNS, kata sandi, FTP, IIS, dan server situs, pengujian dilakukan pada semua perangkat keras dan lunak di sebuah sistem keamanan jaringan. Adapun faktor faktor pendukung seperti tujuan, batasan, dan penyesuaian prosedur yang diperlukan untuk membuat penetration testing lebih maksimal. Selain hal tersebut diperlukan orang yang profesional untuk melakukannya serta pertimbangan biaya yang sesuai dengan kebutuhan. Pada akhirnya diperlukan juga dokumentasi yang jelas serta penjelasan mengenai potensi resiko dan hasil penemuan dari hasil analisa dan uji coba kepada klien atau pihak pengelola layanan.

\section{HASIL DAN PEMBAHASAN}

Pada bab ini penulis akan memaparkan dan menganalisa beberapa celah ataupun kelemahan dari sistem informasi kampus dari beberapa tahap pengujian yang dilakukan antara lain information gatering dan vulnerability scanning.

\subsection{Information Gatering}

Dengan memanfaatkan situs bantuan seperti Domain Tools, informasi mengenai sejarah sebuah domain akan tercantum dan dilampirkan dalam format Whois, dimana informasi seperti tanggal pembuatan domain, nama pemilik domain dan informasi sederhana seperti jenis server yang digunakan, lokasi dan alamat $I P$ Address akan terlampir didalamnya.

\subsection{Vulnerability Scanning}

Di dalam mendeteksi kerentanan pada penelitian ini menggunakan Acunetix untuk mengetahui celah keamanan yang ada di aplikasi berbasis website. Dimana pengembangan aplikasi website pada sistem inforamasi kampus yang sudah dibagun menggunakan PHP dan Wordpress sebagai platform web aplication development. Pada gambar 2 merupakan tampilan hasil scanning menggunakan tools acunetix web vulnerability scanner. 


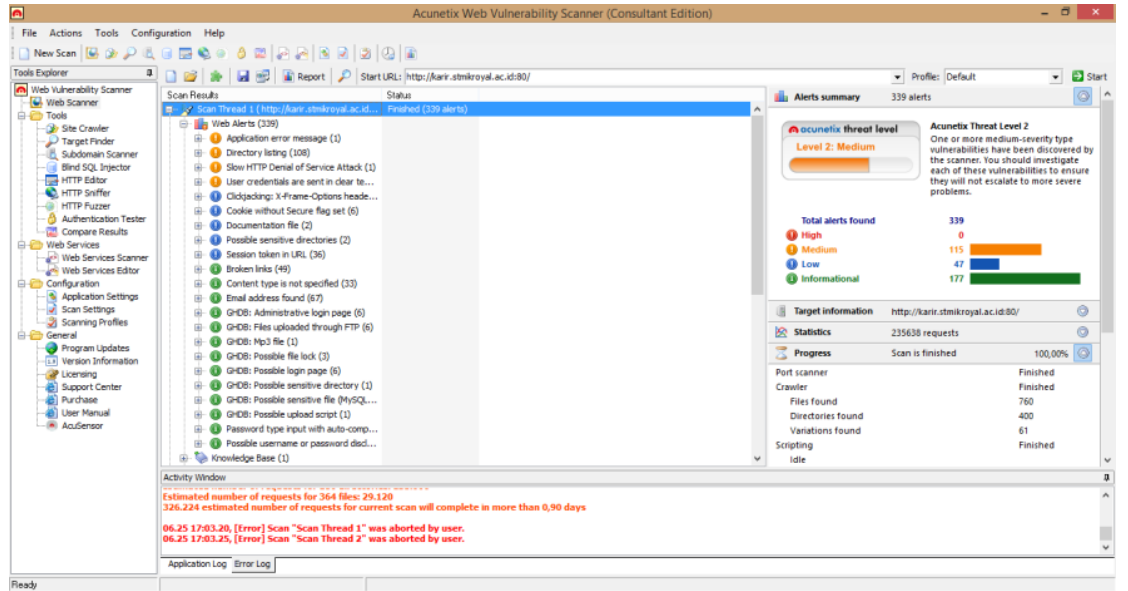

Gambar 2. Hasil Scaning dengan Tools Acunetix Web Vulnerability Scanner Pada Domain 1

Pada gambar 2 merupakan hasil scanning dilakukan pada Domain 1. Berdasarkan scanning yang dilakukan pada domain 1 untuk level kerentanan adalah medium dan web allert 339 diantara kemungkinan bentuk serangan yang akan terjadi berdasarkan hasil penetrasi dengan metode web scanning antara lain Denial of Service Attack (Level Medium) dan Clickjacking (Level Low). Selanjutnya pada Gambar 3 akan menampilkan hasil scanning pada domain yang kedua dari sistem informasi kampus yang di testing.

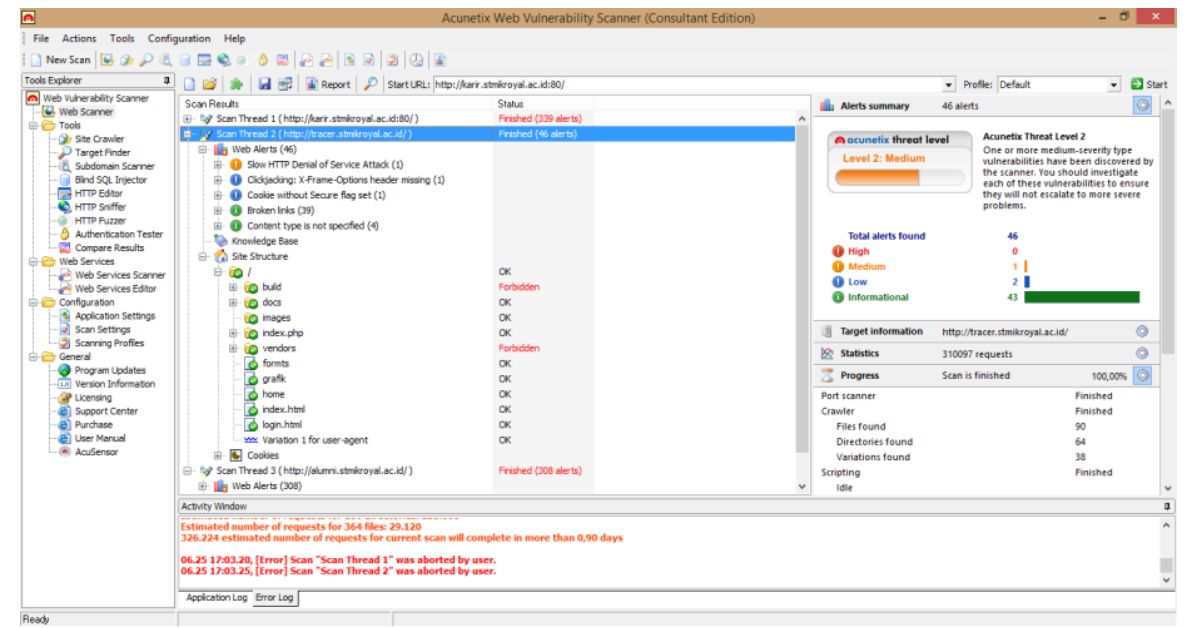

Gambar 3. Hasil Scaning dengan Tools Acunetix Web Vulnerability Scanner Pada Domain 2

Pada gambar 3 merupakan hasil yang didapat dari tahapan web scanning dengan tools Acunetix pada Domain 2. Dimana pada penetration testing pada domain yang kedua ini untuk tingkat kerentanan yang diperoleh adalah medium dengan web allert sebanyak 46, serta kemungkinan serangan yang dapat terjadi diantaranya adalah Denial of Service (level Medium) dan Clickjacking (level Low). Selanjutnya pada gambar 4 dapat dilihat hasil temuan kelemahan pada pada domain lainnya. 


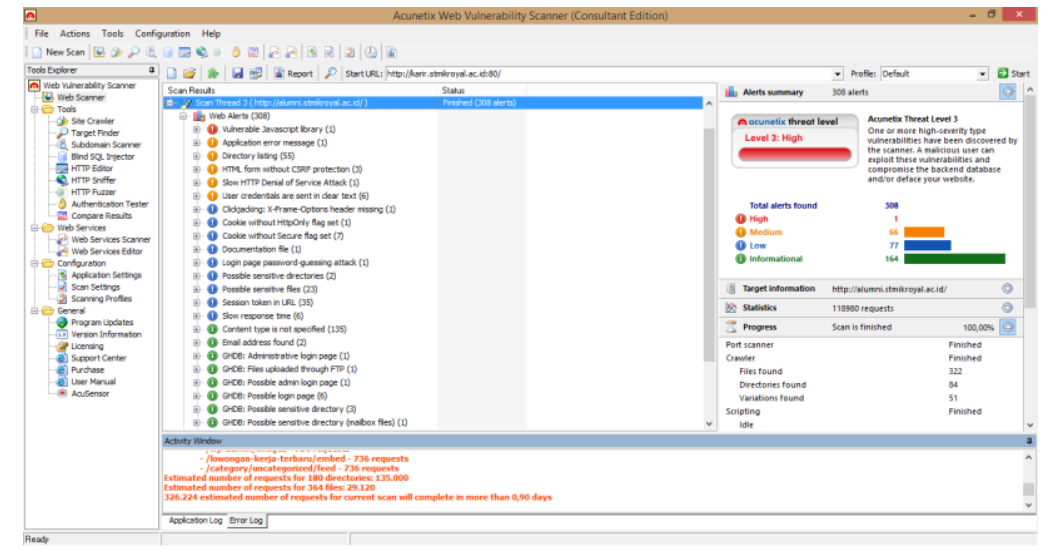

Gambar 4. Hasil Scaning dengan Tools Acunetix Web Vulnerability Scanner Pada Domain 3

Pada gambar 4 telah didapatkan hasil dari vulnerability scanning terhadap aplikasi web pada domain 3, dimana pada domain ke 3 ini untuk level kerentanan adalah high dengan web allert 308 dengan temuan celah kemanan antara lain Vulnerabel Javascript liblary (Level High), CSRF/Cross-site request forgery (Level Medium), Dos (level Medium) dan Clickjacking (level Low). Berikut pada Tabel 1 akan ditunjukkan daftar keseluruhan celah kerentanan pada sistem informasi kampus.

Tabel 1. Celah Keamanan Yang Ditemukan

\begin{tabular}{|c|c|}
\hline Domain & Kerentanan \\
\hline $\begin{array}{llll}\text { Domain } & \text { Pertama } & \text { (Level } & \text { Threat } \\
\text { Medium) } & & & \end{array}$ & $\begin{array}{l}\text { Application Error Message } \\
\text { Directory Listing } \\
\text { Slow HTTP Denial of Service Attack } \\
\text { User Credentials are Sent in Clear Text } \\
\text { Clickjacking X Frame Option Header } \\
\text { Missing } \\
\text { Cookie Without Secure Flag Set }\end{array}$ \\
\hline Domain Kedua (Level Threat Medium) & $\begin{array}{l}\text { Slow HTTP Denial of Service Attack } \\
\text { Clickjacking X Frame Option Header } \\
\text { Missing } \\
\text { Cookie Without Secure Flag Set }\end{array}$ \\
\hline Domain Ketiga (Level Threat High) & $\begin{array}{l}\text { Vulnerable Javascript Library } \\
\text { Application Error Message } \\
\text { Directory Listing } \\
\text { HTML Form Without CSRF Protection } \\
\text { Slow HTTP Denial of Service Attack } \\
\text { User Credentials are Sent in Clear Text } \\
\text { Clickjacking X Frame Option Header } \\
\text { Missing } \\
\text { Cookie Without Secure Flag Set } \\
\text { Login Page Password Guessing Attack } \\
\text { Slow Response Time }\end{array}$ \\
\hline
\end{tabular}

4. KESIMPULAN 
Tidak ada sistem yang benar-benar aman dan sempurna di dunia cyber. Sebagai seorang web programmer maupun server administrator hanya bisa mengupayakan untuk mengamankan web server dengan semaksimal mungkin dan mengurangi risiko-risiko terjadinya celah kerentanan yang bisa dimasuki oleh hacker. Berdasarkan hasil pengujian dengan melakukan penetration testing terhadap 3 domain yang berbeda, terdapat dua domain yang threat levelnya medium dan satu domain yang threat levelnya adalah high. Pada pengujian ini juga telah di temukan beberapa celah kelemaahan atau kerentanan pada sistem informasi kampus yang bisa saja nantinya digunakan untuk memanipulasi file lokal, mengganggu kenerja dari server itu sendiri dengan teknik DoS, melakukan clickjacking serta melakukan CSRF/Cross-site request forgery. Hasil temuan ini akan peneliti jadikan sebagai bahan masukan kepada pihak pengelola sistem informasi kampus untuk segera melakukan perbaikan terhadap kelemahan (Vulnerability) tersebut.

Proses penetration testing yang peneliti gunakan masih sangat memungkinkan untuk dilakukan kembali secara lebih mendalam dan menggunakan metode yang berbeda maupun tools bantu yang lainnya supaya dapat memperoleh hasil pengujian keamanan yang lebih detal lagi.

\section{DAFTAR PUSTAKA}

[1] Babys, J. Y, "Analisis Vulnerable Port Pada Client Pengguna Publik Wifi" Simetris: Jurnal Teknik Mesin, Elektro Dan Ilmu Komputer., 9(1), 261-268, https://doi.org/10.24176/simet.v9i1.2073, 2018.

[2] Bogdanoski M, Shuminoski T dan Risteski A, "Analysis of The SYN Flood DoS Attack" I.J Computer Network and Information Security., No 8, Hal 1-11, DOI: 10.5815/ijenis.2013.08.01, 2013.

[3] Maharani, M. Z., Andrian, H. R., Juli, S., \& Ismail, I, "Analisis Keamanan Website Menggunakan Metode Scanning Dan Perhitungan Security Metriks" E-Proceeding of Applied Science., 3(3), 1775-1782, 2017.

[4] Prabhakar, Shruthi, "Network Security in Digitalization Attacks and Defence" International Journal of Research in Comoputer Application and Robotics., Vol 5, Issue 5, Hal 46-52., 2017.

[5] Shahriar, H., Devendran, V. K., \& Haddad, H, "ProClick: A Framework for Testing Clickjacking Attacks in Web Applications" 144-151. https://doi.org/10.1145/2523514.2523538, November 2013

[6] Syariful Ikhwan, \& Elfitri, I, "Analisa Delay yang Terjadi Pada Penerapan Dimilitarized Zone (DMZ) Terhadap Server Universitas Andalas" Nasional Teknik Elektro Jaringan., 118-124, 2014.

[7] Tarigan, B. V., Kusyanti, A., \& Yahya, W, "Analisis Perbandingan Penetration Testing Tool Untuk Aplikasi Web" Jurnal Pengembangan Teknologi Informasi Dan Ilmu Komputer (J-PTIIK) Universitas Brawijaya., 1(3), 206-214, 2017.

[8] W, Ynanri., Riadi, Imam., \& Yudhana Anton, "Analisis Deteksi Vulnerability Pada Webserver Open Jurnal System Menggunakan OWASP Scanner" JURTI., Vol.2 No. 1, Juni 2018. 